\title{
Novel Design Approach for Simultaneous Energy and Flow Reduction Based on Pinch Analysis with Stream Mixing
}

\author{
Sébastien Lafourcade and Paul Stuart \\ École Polytechnique de Montréal \\ Department of Chemical Engineering \\ PO Box 6079, succ. Centre Ville \\ Montréal (QC), Canada, H3C 3A7 \\ paul.stuart@polymtl.ca
}

\begin{abstract}
Capital intensive industries such as pulp and paper must be committed to improving their operations over the long-term, in a manner leading to minimum environmental impact. Consistent with this goal, a design methodology is proposed here based on thermal pinch analysis which allows for stream mixing, for identifying long-term programs which achieve simultaneous flow and energy reduction. The overall framework for the design methodology takes into account current techno-economic objectives, their variation over time, and eventual opportunities for the implementation of zero effluent operation. The methodology is illustrated by application at a TMPnewsprint mill.
\end{abstract}

\section{Introduction}

Each year the pulp and paper industry faces increasingly stringent environmental regulations and permit requirements. It is critical that mills design process changes for simultaneous reduction of water and energy consumption over the long-term, in order to meet these environmental requirements at minimum cost.

The Kyoto protocol, ratified in Canada but not yet manifested in regulation, will undoubtedly influence mill planning activities in the coming years. Attempts by mills to reduce energy consumption have historically been motivated by the desire to achieve energy cost reductions in the short term, but now these measures are becoming part of the industry's longerterm strategic planning. Reducing water consumption in process operations is also an important strategic objective which will allow mills to meet longer-term effluent objectives cost-effectively. In the case of integrated newsprint mills, the ultimate goal of zero effluent treatment operation is technically feasible, and should be considered an important ultimate objective. By considering these important goals, the pulp and paper industry is demonstrating a sustained commitment to minimum environmental impact manufacturing.

Thermal pinch analysis has become an indispensible method to tackle industrial energy issues [8]. Originally employed as a method for the design of heat exchange circuits, it has evolved into a more generalized methodology for the energy-efficient design of new facilities and for retrofitting existing systems [7]. One of the main shortcomings with the thermal pinch technique is that it only considers noncontact heat exchange, and does not take heat exchange by stream mixing into consideration. Heat and mass transfer interactions for a given process are not systematically taken into account in the technique. Thus in its classical form, thermal pinch analysis is not well-suited for the identification of opportunities for simultaneous reductions in water and energy consumption.

Thermal pinch analysis has been used for several industrial applications, in particular with respect to energy targeting [5], the design of heat exchange networks [10], overall site analysis including reductions in greenhouse gas emissions [1], and for retro-fitting existing energy networks [3][9]. An analogous mass pinch analysis has been developed [4], however few studies have focused on the simultaneous reduction of energy and flow using pinch analysis. Savulescu et al. [12] suggested a method to improve flow networks that is based on composite curves and the mixing of similar streams, but the method excludes exchanges due to the mixing of hot and cold streams. Savulescu et al. [11] proposed a methodology whereby heat and mass analyses are performed separately, and then combined afterwards. Berntsson et al. [2] used thermal pinch analysis to extract surplus energy in 
order to carry out effluent reduction scenarios. However, in none of these cases was a simultaneous analysis carried out. In each case, pinch analysis was used in its classical form with its inherent limitations.

In this article, we present a novel approach based on thermal pinch analysis which allows for heat exchange by stream mixing, in a practical framework to address short-term flow and energy reduction goals from a long-term perspective. This new methodology is applied for the case of eventual zero effluent operation in a newsprint mill.

\section{Summary of Overall Framework}

In order to achieve minimal energy consumption and eventually zero effluent operation, the proposed design approach involves the application of a simultaneous flow and energy analysis. The framework also considers short-term objectives based on long-term planning, as well as the variation of techno-economic constraints and environmental regulations over time. This approach would be implemented in 3 steps as illustrated in Figure 1a:

- Step 1: The implementation of in-plant improvement projects and technologies that have already been proven in industry. The technological risk of these projects is low.

- Step 2: The implementation of in-plant improvement projects and technologies that may or may not have been widely implemented in industry, and that are associated with innovative procedures or technologies. This approach typically considers projects having some level of risk.

- Step 3: The implementation of projects necessary for zero effluent and minimal energy consumption. The risk is higher in this case.

The key criterion for establishing the capital sending program resulting from Step 1 is the return on investment (ROI), which depends on the company's investment priorities, project capital costs, and the economic context including energy costs. The technical program associated with the ROI criterion is based on factors which change over time, including the real or perceived risks associated with nearly-proven flow and energy saving technologies. Mills should execute Step 1 every few years and re-establish their energy and flow reduction program.

Figure $1 \mathrm{~b}$ indicates a point in time where major environmental constraints become the driving force for energy and flow reduction. This refers to the situation where a mill requirement contained in a regulation or permit makes it more cost-effective to achieve zero effluent operation rather than to treat effluent for discharge into receiving waters.

For Steps 2 and 3, the key criterion for the capital spending program is minimum project cost, since at this point, process changes are essential for continued operation (meeting environmental regulations is "the cost of doing business"). Thus a mill is more likely to accept risk in order to reduce the overall cost of the environmental project.

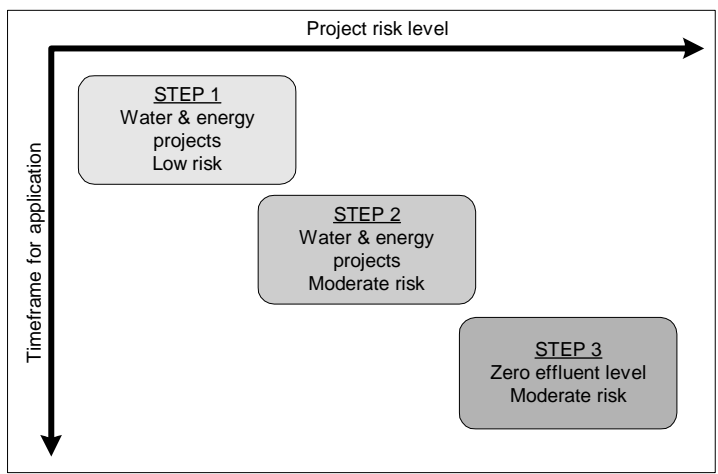

(a)

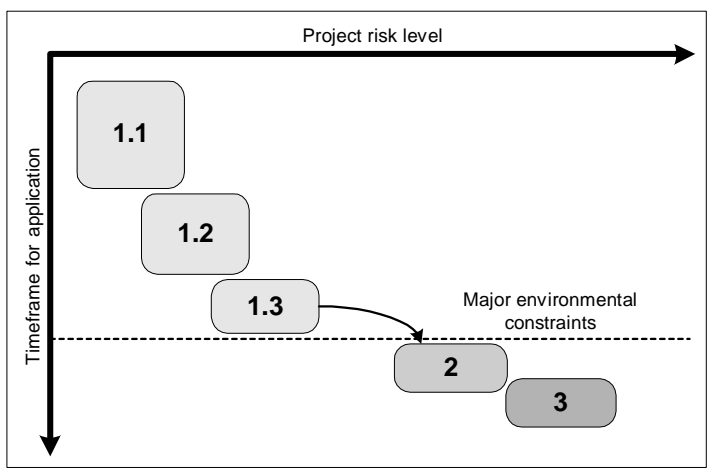

(b)

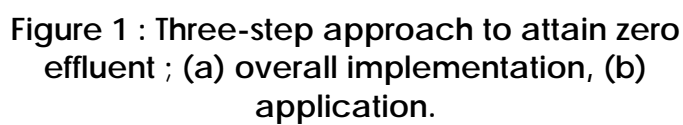

\section{Study Objectives}

The objective of this work was to develop a design methodology for the simultaneous analysis of water and energy, involving a novel application of thermal pinch analysis. The application of this methodology should lead to improvement programs aimed at achieving minimum energy consumption, and zero effluent operation for the case of integrated newsprint mills. The framework should allow an industrial site to meet specific short-term goals using a long-term perspective. The technological solutions, associated 
costs, implementation of projects over time, and techno-economic constraints facing the mill should be considered within the framework.

The methodology was developed in 4 steps as summarized in Figure 2, including 1) basic methodology development, or formulation of the thermal pinch based methodology for identifying process strategies for energy and flow reduction, 2) techno-economic analysis carried out with a cost estimation tool, 3) validation and 4) application for the goal of zero effluent operation. This article focuses on the first step of this overall methodology, and its case study validation.

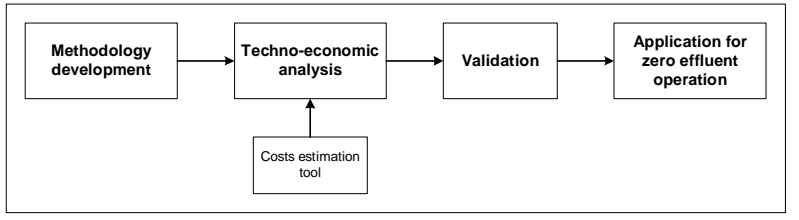

Figure 2 : Summary of methodology development

\section{Study Methodology}

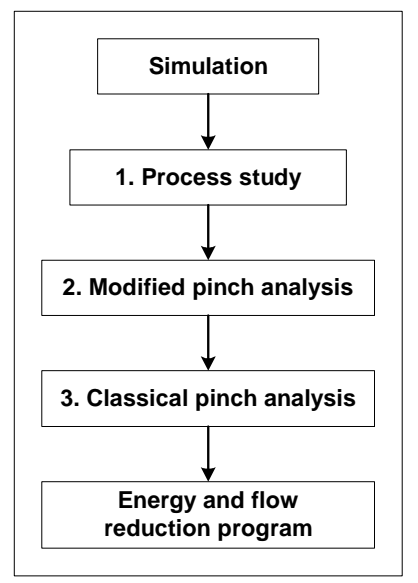

\section{Figure 3 : The 3 phases of the flow and energy analysis methodology.}

The 3 phases of the methodology for the flow and energy analysis are summarized in Figure 3. First, an open-ended process study identifies conventional projects and takes the process specifics into account. Next, a modified pinch analysis identifies stream mixing opportunities for flow and energy reduction. Finally, a classical pinch analysis identifies indirect heat exchange projects.

\section{Thermal pinch techniques}

Figure 4 shows the typical results of the pinch analysis. In enthalpy-temperature diagram, the hot composite curve represents the amount of available heat and the cold one represents the amount of required heat. At the pinch point, the two curves are separate by the minimum temperature difference required in the process heat exchangers, $\Delta \mathrm{T}_{\min }$. The layout of the curves provides the energy targets of the process, namely the minimal required heating and the minimal required cooling.

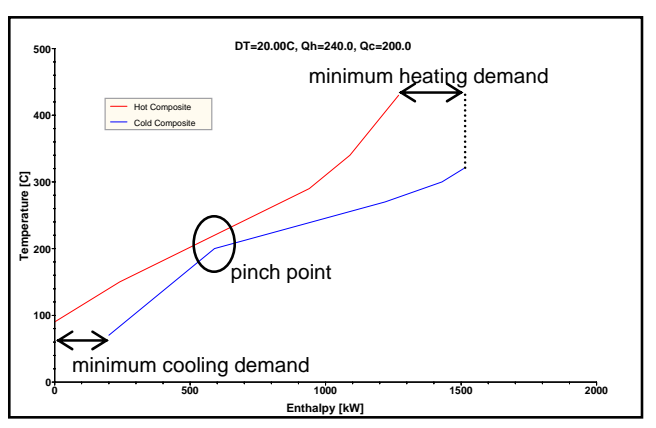

Figure 4 : Example of composite curves.

\section{Process Simulation}

The process simulation comprises mill-wide steady state heat and mass balances under various process operating scenarios, which are necessary for data extraction in the thermal pinch analysis, and which is useful to later assist in the evaluation of millwide impacts due to proposed energy and flow reduction projects. The simulation must be validated, either formally through data processing and reconciliation techniques, or at least by consultation with mill personnel.

\section{Phase 1: Process Study}

The process study allows for the identification, by inspection or by benchmarking, of specific projects within a process that may fall outside the pinch analysis domain. Three major types of improvement projects are considered:

- proven technology projects (e.g., installation of a more energy-efficient piece of equipment),

- energy and flow reduction projects that cannot be identified by pinch analysis (e.g., potential to use the excess energy dissipated by certain types of equipment such as vacuum pumps), and

- advanced modernization projects (e.g., emerging or risky technologies that have not yet been widely implemented such as ultrafiltration membranes) 
Those projects or combinations of projects that are retained become "Base Cases" for the subsequent phases summarized in Figure 5.

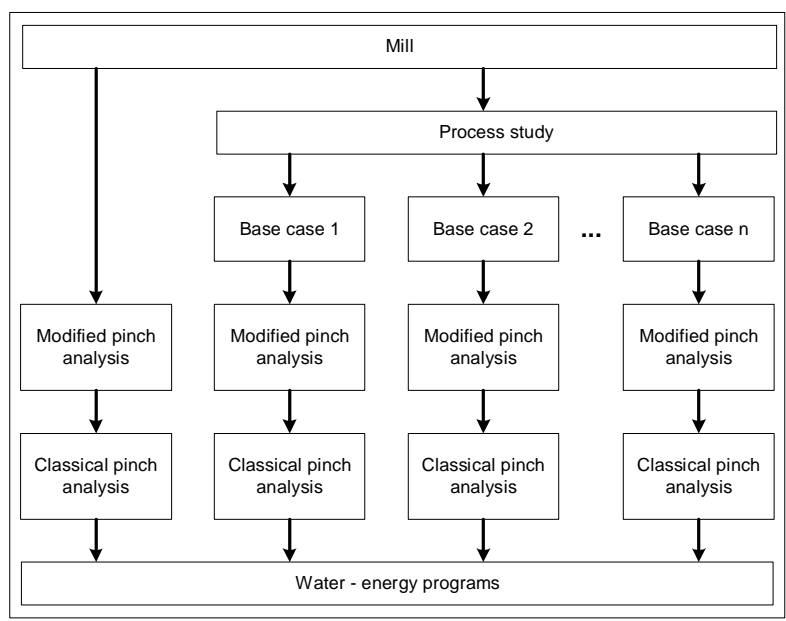

Figure 5 : Development of water-energy improvement projects.

\section{Data Extraction}

Data extraction must be performed for both the thermal pinch analysis with stream mixing, and the classical pinch analysis. Few guidelines exist for data extraction, and good process knowledge is critical in order to address this step appropriately. The hot and cold streams involved in heat exchange processes are extracted, along with mixing streams. The two sets of extracted streams must meet requirements which may be different for the two phases. Considerations for data extraction include threshold values for potential energy transfer and temperature gradients (below which streams are not extracted), number of streams extracted, separation according to processes or departments, etc.

Phase 2: Thermal pinch analysis with stream mixing

The modified thermal pinch analysis consists of 5 steps as follows:

1. extraction of streams from the process simulation, which has been modified by the implementation of projects used to create the different base cases,

2. generation of a classical heat exchange network using $\Delta \mathrm{T}_{\min }=0^{\circ} \mathrm{C}$,

3. application of design rules related to process and to techno-economic factors, in order to identify heat exchange opportunities that can involve stream mixing,
4. process evaluation of the selected mixing projects, including by their implementation in the process simulation,

5. identification of possible stream mixing projects to be considered in subsequent steps.

\section{Phase 3: Classical pinch analysis}

The classical thermal pinch analysis also consists of 5 steps as follows:

1. extraction based on the simulation, which has been modified by the implementation of the process study projects and the retained mixing projects,

2. generation of a classical heat exchange network for a value of $\Delta \mathrm{T}_{\min }$ to be determined based on the process,

3. application of design rules related to the process and to techno-economic factors in order to select the indirect exchangers of interest,

4. evaluation of the selected indirect heat exchange projects,

5. implementation of the retained indirect heat exchange projects in the process simulation to evaluate potential mill-wide impacts.

\section{Flow and Energy Reduction Projects}

Energy and flow reduction programs thus include the following projects: those derived from process analysis, stream mixing projects, and indirect heat exchange projects. Several programs may be obtained for the same case study, depending on the results of the classical and modified analyses. These must each be analyzed holistically to establish their combination that best meets the mill's ROI objective.

\section{Case Study Validation of the Methodology}

The methodology was applied at an integrated thermo-mechanical pulp (TMP) newsprint mill, located in northern Québec (Canada), which produces 550 tons/day of newsprint [6]. In addition to the objectives related to demonstrating the proposed methodology, the case study mill had 3 process objectives: to reduce the temperature of the mill effluent in summer, to reduce the steam consumption in winter, and to reduce the overall temperature of the TMP process streams.

Figure 6 presents a schematic of a generic TMP newsprint mill, which is characterized by high water usage, high electrical energy and steam consumption levels, as well as by high quantities of low grade 
residual energy in the process. Due to the high level of integration of these processes, the flow and energy interactions at the mill are significant, and heat transfer by stream mixing is a common practice.



Figure 6 : Simplified diagram of an integrated TMP newsprint mill.

Following the process study portion of the methodology, two additional base case were identified. One was based on a project involving steam recovery system at the TMP plant, and the other project involved vacuum pump seal water recirculation. The two next phases in the methodology were therefore applied to four case studies: two scenarios based on the initial mill configuration (summer and winter), plus two base case identified by the process study. The parameters used for the classical and modified pinch analyses are displayed in Table 1. The threshold values for transferred energy $\left(\mathrm{Q}_{\min }\right)$ and temperature gradient $\left(\Delta \mathrm{T}^{*}\right)$ were selected based on a compromise between the number of extracted streams and recuperation potential. The analysis encompassed most of the mill, including the process as well as the water, heating, and condensate networks. The value of $\Delta \mathrm{T}_{\min }$ for the modified analysis was based on the principle of direct exchange, and that for the classical analysis was determined from the difference in average temperatures observed in the process exchangers. The software program Super Target 5 from the company Linnhoff March was used to generate the heat exchange networks for both phases.

\section{Table 1 : Parameters used for phases 2 and 3 of the methodology (modified and classical pinch analyses).}

\begin{tabular}{|c|c|c|}
\hline Parameters & Modified Analysis & Classical Analysis \\
\hline $\mathrm{Q}_{\min }$ & $900 \mathrm{~kW}$ & $900 \mathrm{~kW}$ \\
\hline$\Delta \mathrm{T}^{*}$ & none & none \\
\hline scope & entire mill & entire mill \\
\hline$\Delta \mathrm{T}_{\min }$ & $0^{\circ} \mathrm{C}$ & $20^{\circ} \mathrm{C}$ \\
\hline
\end{tabular}

A set of rules developed for the selection of mixed streams is summarized in Table 2.

\section{Table 2 : Design Considerations for mixed stream exchangers (modified pinch analysis) and for indirect heat exchangers (classical pinch analysis).}

\begin{tabular}{|l|l|}
\hline \multicolumn{1}{|c|}{ Modified Analysis } & \multicolumn{1}{c|}{ Classical Analysis } \\
\hline $\begin{array}{l}\text { The heat exchanger with stream } \\
\text { mixing does not breach pinch } \\
\text { guidelines. }\end{array}$ & $\begin{array}{l}\text { The indirect heat exchanger } \\
\text { does not breach pinch } \\
\text { guidelines. }\end{array}$ \\
\hline $\begin{array}{l}\text { Mixing does not excessively } \\
\text { contaminate (dissolved solids, } \\
\text { suspended solids, temperature) } \\
\text { either stream in its final } \\
\text { application. }\end{array}$ & $\begin{array}{l}\text { Heat exchange is technically } \\
\text { feasible and practical (e.g. } \\
\text { accessibility of the streams) }\end{array}$ \\
\hline $\begin{array}{l}\text { When the mixed streams are } \\
\text { recycled, the quality of the recycled } \\
\text { stream must be acceptable for the } \\
\text { application. If treatment is } \\
\text { required, then this must be } \\
\text { considered and technically feasible. }\end{array}$ & $\begin{array}{l}\text { The mixing of streams is } \\
\text { feasible from a geographical } \\
\text { point of view. }\end{array}$ \\
\hline $\begin{array}{l}\text { Fresh water is not used for an } \\
\text { application that requires lower } \\
\text { quality water. }\end{array}$ & \\
\hline $\begin{array}{l}\text { The mixing of streams does not } \\
\text { result in loss of fibers or chemical } \\
\text { products. }\end{array}$ & \\
\hline $\begin{array}{l}\text { The mixing of streams is feasible } \\
\text { from a geographical point of view. }\end{array}$ & \\
\hline
\end{tabular}

Figure 7 illustrates 3 mixing configurations that can be considered to replace an indirect exchanger (Figure 7a). 1 and 3 are sources (ex.: fresh water intake, effluent), 2 and 4 are applications (ex.: warm water use, effluent treatment) and " $\mathrm{M}$ " is a mixing point.

- mixing with reallocation (Figure 7b): after mixing, the flow is redirected towards the initial applications.

- mixing without reallocation (Figure 7c): the total mixed volume is sent towards a single application. This option may require a complementary mixing system to meet the needs of the remaining application.

- recirculation (Figure 7d) : this is a specific case of mixing without reallocation, whereby the source of one stream and the application of the other stream are eliminated. Typically, recirculation would occur between an effluent stream and a fresh water stream that needs to be preheated. 


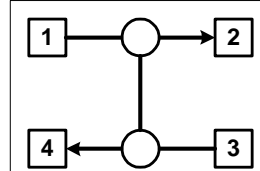

(a)

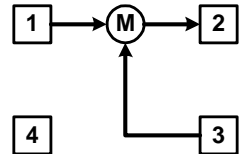

(c)

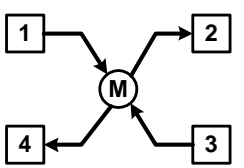

(b)

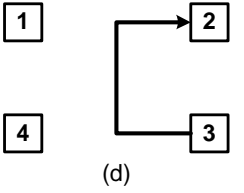

\section{Figure 7 : Process altematives for converting an indirect exchanger in a stream mixing.}

For these three types of mixing, the quality of water required for each receiving application must be evaluated based on process knowledge, industry practice, and the process fundamentals. When stream treatment was necessary, the potential mixing scenario can be selected only if the treatment is technically feasible. The selection of indirect heat exchange projects was subject to fewer constraints (table 2). One critical factor is the use of heat exchangers for streams containing a high concentration of fibers.

Out of the 4 energy and flow reduction programs obtained in the case of the TMP-newsprint case study mill, 2 programs met all 3 specific mill objectives and furthermore, they identified flow and energy reduction projects that are compatible with the long-term goals of the mill. At this stage of the work, costs were not estimated. Instead, hypotheses were made based on process knowledge and available technologies. For example, stream mixing is considered less expensive than a corresponding indirect heat exchanger. Another important economic consideration was the eventual cost of water treatment. The techno-economic elements brought to light in this study component will be systematically addressed in future work.

\section{Comparison with the classical application of thermal pinch analysis}

A classical pinch analysis was applied at the case study mill, and the results were compared to those obtained from the application of the modified methodology. The parameters used for the analysis are presented in Table 3. The application of a classical pinch analysis obviously leads to a program involving indirect heat exchangers, does not yield any opportunities for effluent reduction, and does not consider the potential to recuperate energy from certain pieces of equipment.
Table 3 : Parameters used for the application of a classical pinch analysis alone.

\begin{tabular}{|c|c|}
\hline Parameters & Classical analysis alone \\
\hline $\mathrm{Q}_{\min }$ & $900 \mathrm{~kW}$ \\
\hline$\Delta \mathrm{T}^{*}$ & none \\
\hline Extracted streams & $\begin{array}{c}\text { Warm water network and streams related } \\
\text { to specific mill objectives }\end{array}$ \\
\hline$\Delta$ Tmin & 5 and $28^{\circ} \mathrm{C}$ \\
\hline
\end{tabular}

\section{Sensitivity analysis}

The objective of the sensitivity analysis was to vary critical study parameters in order to observe in a qualitative way, their impact on the results, and gain a better understanding as the first step towards generalization of the methodology.

The parameters that were manipulated for the modified and classical pinch analyses are summarized in Table 4: threshold values of transferred energy $\left(\mathrm{Q}_{\min }\right)$ and temperature $\left(\Delta \mathrm{T}^{*}\right)$ for an extracted stream, the imposed temperature differences within the network $\left(\Delta \mathrm{T}_{\min }\right)$, the scope of the study, and the extraction of «non-conventional» streams (chip flow, warm air streams, etc.). The results from the pinch technique, including the composite curves and the types of projects obtained, were evaluated.

Table 4 : Parameters manipulated for the sensitivity analysis

\begin{tabular}{|c|c|}
\hline Parameters & Values \\
\hline Qmin $(\mathrm{kW})$ & $0,900,1500(\mathrm{~kW})$ \\
\hline$\Delta \mathrm{T}^{*}\left({ }^{\circ} \mathrm{C}\right)$ & $0,10,20\left({ }^{\circ} \mathrm{C}\right)$ \\
\hline$\Delta \mathrm{Tmin}\left({ }^{\circ} \mathrm{C}\right)$ & $0,15,20,25\left({ }^{\circ} \mathrm{C}\right)$ \\
\hline Scope of the study & $\begin{array}{c}\text { entire mill, TMP plant, paper machine, } \\
\text { water network, warm water network }\end{array}$ \\
\hline $\begin{array}{c}\text { « Non-conventional } \\
\text { streams }\end{array}$ & yes, no \\
\hline
\end{tabular}

Relationship between the resulting projects and the composite curves

In order to understand the sensitivity analysis results, the structure of the composite curves has first to be studied. Figure 8 shows the composite curves obtained for the base case. The pinch point results from the TMP plant streams. Above the pinch point, there are machine condensates, and below, there are residual energy streams (warm air and effluent), fresh water streams, and other streams from the water network. 


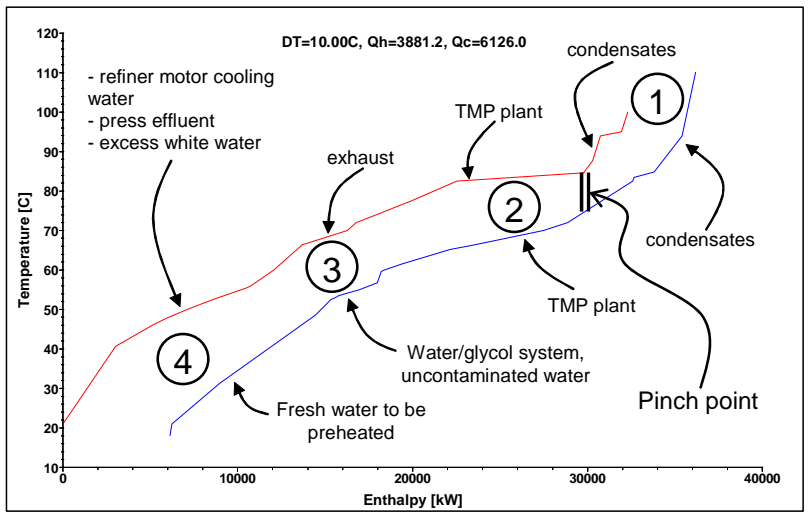

Figure 8 : Composite curves for the base case

Whether for the modified or the classical analysis, vertical heat exchanges are favored during network construction. Therefore, the identified exchanges are closely linked to the shape of the composite curves. Four large project groupings were identified based on the experimental results. They correspond to the zones indicated in Figure 8, summarized as follows:

(1) direct or indirect exchanges between condensates (above the pinch): typically already existing in the mill.

(2) direct exchanges between TMP plant streams (around the pinch zone): the resulting mixing projects are not new, but rather confirm the current mill configuration.

(3) direct or indirect exchanges between warm air and fresh water/water-glycol (below the pinch): mixing is not possible due to the nature of the streams, and indirect exchanges between these streams already exist at the mill.

(4) direct or indirect exchanges between the effluent and fresh water (below the pinch): these are the most promising opportunities like effluent stream to the machine's warm water loop.

In each of these groupings, three or four projects are predominant, and they meet the study objectives. The remaining projects are marginal with respect to energy exchanged and based on a preliminary process evaluation, may have process impacts.

\section{Relationship between identified energy and flow reduction projects, and study parameters}

The detailed results of the sensitivity analysis are not given here. The conclusions are the following:

- The TMP plant streams are not very sensitive to the manipulated parameters $\left(\mathrm{Q}_{\min }, \Delta \mathrm{T}^{*}\right.$ and $\left.\Delta \mathrm{T}_{\min }\right)$,
- Consequently, the pinch point and the shape of the curves are relatively stable.

- Sections of the curves may be shortened or lengthened depending on values of $\mathrm{Q}_{\min }$ and $\Delta \mathrm{T}^{*}$, but the four zones previously described do not change. This can be explained by the presence of streams in each of these zones that are significant enough to always warrant extraction, regardless of the parameters.

- The breakdown of the analysis according to department or process section further confirms this. The individual analyses of the TMP plant and of the water network yield the same projects. Furthermore, this experiment confirms that the energy opportunities at the TMP plant and water network levels are relatively independent.

- Table 5 gives the parameters for the modified pinch analysis for best results.

Table 5 : Final parameters formodified pinch analysis

\begin{tabular}{|c|c|}
\hline Parameters & Values \\
\hline Qmin $(\mathrm{kW})$ & $900(\mathrm{~kW})$ \\
\hline$\Delta \mathrm{T}^{*}\left({ }^{\circ} \mathrm{C}\right)$ & $0\left({ }^{\circ} \mathrm{C}\right)$ \\
\hline$\Delta \mathrm{Tmin}\left({ }^{\circ} \mathrm{C}\right)$ & $0\left({ }^{\circ} \mathrm{C}\right)$ \\
\hline Scope of the study & TMP plant and warm water network \\
\hline $\begin{array}{c}\text { « Non-conventional } \\
\text { streams }\end{array}$ & no \\
\hline
\end{tabular}

Modification of the application of phase 3 of the methodology

As defined previously, Phase 3 of the methodology (classical pinch analysis) is applied to the entire mill in order to generate a network from which indirect heat exchange projects can be selected. The sensitivity analysis of this phase yielded the following results

1. the projects identified by the process study and the modified pinch analysis meet, for the most part, the flow and energy objectives, and

2. the classical pinch analysis, applied in the framework described above, is not effective in this context. After the modified analysis step was completed, either the energy goals were not entirely met (e.g., insufficient reduction of steam in winter), or undesirable side effects occurred (e.g., new heating demands).

It would therefore be more advantageous to design a network to meet those demands specifically. 


\section{Long-term water-energy reduction program}

The long-term objective of integrated newsprint mills should be to implement zero effluent operation over the long-term, in the most cost-effective manner. The chemical load added to mechanical pulping and newsprint processes is relatively small, and thus the build-up of chemicals can be controlled at a reasonable cost. Thus in the longer-term, it may likely be less costly to treat-and-recycle effluent than to treat-anddischarge effluent in the case where a low concentration of a single parameter can be difficult and expensive to achieve. The Phase 3 methodology was thus considered for identifying strategies to obtain zero effluent operation, however have yet to be quantitatively addressed.

Two process strategies were selected to examine this possibility: 1) effluent segregation, ultrafiltration membrane treatment, and effluent recirculation back to process, and 2) effluent evaporation. Membrane treatment is a flexible option that permits treatment of a wide range of process streams. This technology is currently being employed in a small number of applications in the pulp and paper industry. On the other hand, evaporation is commonly used at chemical pulp mills. Two Canadian market mechanical pulp mills currently employ evaporator technology to operate with zero effluent.

Table 6 lists the ideal conditions for the mill to reach to consider either of the two strategies. In both cases, the total effluent flowrate should be minimized in order to reduce the size, and hence the cost, of the equipment required for zero effluent operation. For evaporation, the final effluent temperature should be maximized for the best efficiency. For treatment and recirculation using membranes, there must be segregation according to contamination levels, as well as thermal segregation.

Table 6 : Target conditions for considening the implementation of zero effluent operation

\begin{tabular}{|l|c|c|}
\hline \multicolumn{1}{|c|}{ Options } & Effluent flow & Effluent temperature \\
\hline Effluent evaporation & Minimum & Maximum \\
\hline $\begin{array}{l}\text { Treatment and } \\
\text { recirculation }\end{array}$ & Minimum & Thermal segregation \\
\hline
\end{tabular}

\section{Results}

The overall methodology was applied to a TMPnewsprint mill. The process study yielded 8 base cases, and the application of the modified thermal pinch analysis resulted in a total of 26 possible improvement programs. An initial screening reduced this number to 10 , summarized in Table 7. The results from these 10 programs, before the classical pinch analysis step, are presented in Figures 9 (summer) and 10 (winter).

Table 7 : Description of the 10 selected programs

\begin{tabular}{|c|c|c|c|c|c|c|c|c|c|c|}
\hline Projects & $\bar{a}$ & 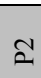 & $\curvearrowleft$ & ڤ. & $\frac{0}{a}$ & $\frac{2}{2}$ & $\frac{n}{a}$ & $\frac{\infty}{a}$ & $\frac{a}{a}$ & ָิ \\
\hline $\begin{array}{l}\text { TMP steam } \\
\text { recuperation }{ }^{1}\end{array}$ & & & $x$ & $X$ & & & & $X$ & $x$ & $X$ \\
\hline $\begin{array}{l}\text { Vacuum pump seal } \\
\text { water recirculation }^{1}\end{array}$ & & & & & & $X$ & $X$ & $X$ & $x$ & $X$ \\
\hline $\begin{array}{l}\text { Excess white water } \\
\text { purged at TMP plant }\end{array}$ & & & & & $X$ & & & $X$ & $X$ & $X$ \\
\hline $\begin{array}{l}\text { Recirculation of } \\
\text { cooling water from } \\
\text { the TMP motors }\end{array}$ & & $\mathbf{X}$ & & $X$ & $X$ & & $X$ & & $X$ & $x$ \\
\hline $\begin{array}{l}\text { Recirculation of the } \\
\text { treated pressate }\end{array}$ & & $X$ & & $X$ & $X$ & & & & & \\
\hline $\begin{array}{l}\text { White water chip } \\
\text { washing }^{2}\end{array}$ & & & & & & & & & & $X$ \\
\hline
\end{tabular}

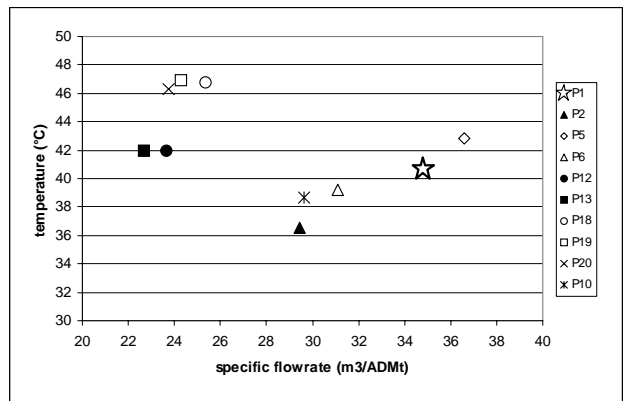

(a)

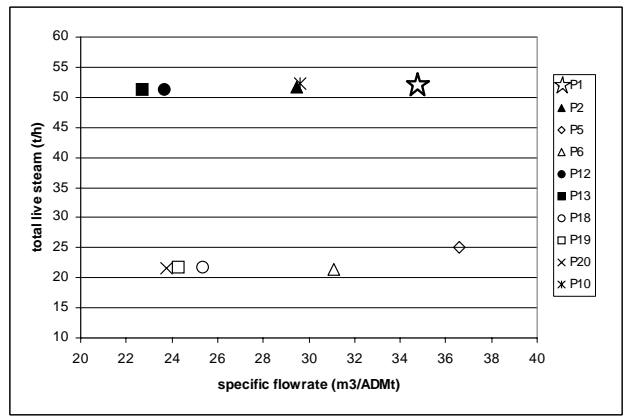

(b)

Figure 9 : Impacts of the improvement programs before the classical pinch analysis step (summer); (a) effiluent temperature and (b) steam consumption 


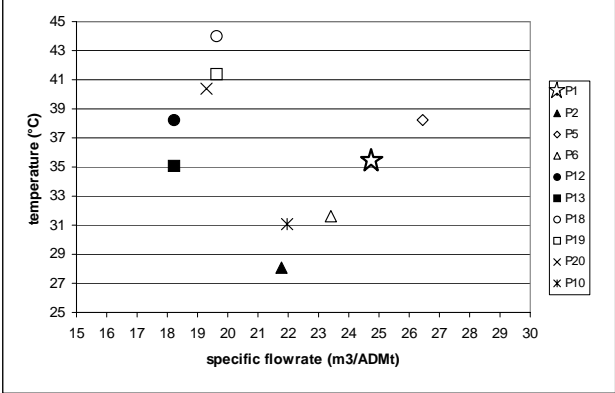

(a)

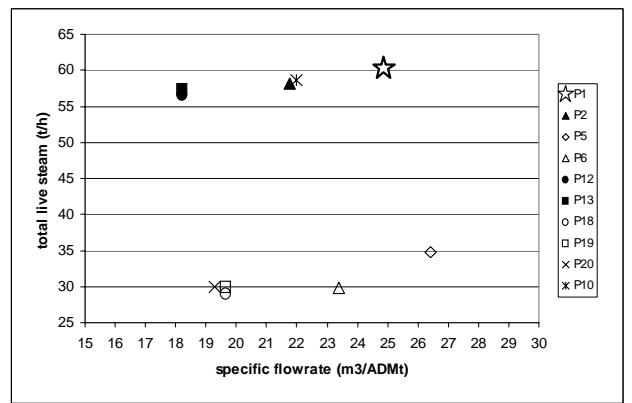

(b)

Figure 10 : Results of the improvement programs before the classical analysis step (winter); (a) effluent temperature and (b) steam consumption

The P1 program represents the current mill configuration. All programs, except P5, result in a significant reduction in the effluent flowrate. There are two reduction levels: the first level, around $15 \%(\mathrm{P} 2$, P6, P10), results mainly from recirculation projects derived from the modified analysis, and the second level, around 30\% (P12, P13, P18, P19, P20), results mainly from the recirculation of vacuum pumps sealing water, a project identified during the process study. For practical reasons, this last project could not have been identified by pinch analysis, which illustrates the benefit of performing a preliminary process analysis. Two levels can also be noted with respect to effluent temperature, for similar reasons. The recirculation projects derived from the modified analysis result in a reduction in effluent temperature, while the vacuum pumps water reciculation increases it. There is a complementary aspect to these two analyses, which provide two different alternatives for the application of zero effluent strategies: one involving recirculation, the other evaporation. From a steam consumption perspective, there are also two reduction levels. The first corresponds to the current consumption level for the mill (P1, P2, P12, P3, P10), and the second corresponds to a reduction of around $50 \%$ (P5, P6, P18, P19, P20). The difference between these two groups is due to the TMP plant steam recovery project, which has a major impact on the consumption of live steam. In comparison, the other projects only result in marginal reductions. If a comparison is made between two programs that only differ with respect to the steam recovery project (i.e., P2 and P6, P12 and P18), it is clear that steam recovery results in a significant increase in the flowrate and temperature of the effluent, due to the reject of a TMP condensate. The trends in the winter results are approximately the same as those observed in summer. However, in winter, the recirculation projects have a greater impact on the energy consumption, since more steam is required to preheat fresh water than in summer.

In addition to the potential reduction in energy consumption, two groupings of selected programs also facilitate the implementation of zero effluent strategies, which involve a significant reduction in effluent, an increase in the effluent temperature for evaporation (P12, P13, P18, P19, P20), or a decrease for thermal segregation (P2, P6 et P10). Although the differences between the programs within a single grouping can be subtle, they become more apparent in the technoeconomic study.

\section{Indirect heat exchanger network}

The projects obtained allow reaching target conditions for the implementation of zero effluent operation. As mentioned earlier, the classical pinch analysis must then be applied to address the energy goals that were not entirely met or undesirable side effects occurred. Table 8 summarizes the resulting design objectives for the network. Since the application of the classical analysis requires technical and economic parameters, this last phase of program construction will occur during the techno-economic analysis.

\section{Table 8 : Objectives of the classical themal pinch analysis for each selected program}

\begin{tabular}{|c|c|c|c|c|c|c|c|c|c|c|}
\hline Projects & $\bar{a}$ & $\Sigma$ & 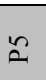 & $\stackrel{2}{2}$ & $\stackrel{ }{a}$ & $\frac{I}{a}$ & $\frac{m}{a}$ & $\frac{\infty}{a}$ & $\frac{\partial}{a}$ & હે \\
\hline \begin{tabular}{|l|} 
Effluent \\
cooling
\end{tabular} & $X$ & & $x$ & $x$ & & $X$ & $x$ & $\mathrm{X}$ & $x$ & $\mathrm{X}$ \\
\hline $\begin{array}{l}\text { TMP loop } \\
\text { cooling }\end{array}$ & $X$ & $X$ & & & $X$ & $X$ & $X$ & & & \\
\hline \begin{tabular}{|l|} 
Heating of \\
fresh water for \\
showers
\end{tabular} & $X$ & & $X$ & & & & & & & \\
\hline \begin{tabular}{|l|} 
Heating of \\
machine white \\
water
\end{tabular} & & & $X$ & $X$ & & & & $\mathbf{X}$ & 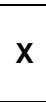 & $x$ \\
\hline \begin{tabular}{|l|} 
Heating of \\
TMP facility \\
(winter)
\end{tabular} & & & $X$ & $X$ & & & & $X$ & $X$ & $\mathbf{X}$ \\
\hline $\begin{array}{l}\text { Heating of } \\
\text { drying air }\end{array}$ & $X$ & $\mathbf{X}$ & $x$ & $\mathrm{X}$ & $X$ & $\mathbf{X}$ & X & $\mathrm{X}$ & $\mathbf{X}$ & $\mathbf{X}$ \\
\hline
\end{tabular}




\section{Conclusions}

A practical design methodology based on thermal pinch analysis allowing for stream mixing has been proposed to identify simultaneous, long-term flow and energy reduction projects. There are three phases involved in the methodology: an open-ended process study, a modified pinch analysis to identify heat exchange projects by stream mixing, and a classical pinch analysis to identify indirect heat exchange projects. The framework for the application of the methodology was defined, which takes into account current techno-economics, their variation with time, and possible future environmental requirements.

In this article, the first part of the development of the methodolgy is presented via its application to a TMP newsprint mill. The results of the study are as follows:

- design rules specific to this type of mill were developed to support the methodology,

- a sensitivity analysis helped to highlight the important parameters in the methodology and to generalize certain results,

- flow and energy reduction programs were developed which were consistent with eventually achieving zero effluent operation in the long term.

\section{Acknowledgements}

This work was supported by the Natural Sciences and Engineering Research Council of Canada (NSERC) Environmental Design Engineering Chair at École Polytechnique. We would like to thank the mill and corporate personnel of Abitibi-Consolidated Inc. for their close collaboration during all phases of this work.

\section{References}

[1]. H. Axelsson, A. Asblad, and T. Berntsson. "New methodology for greenhouse gas reduction in industry through improved heat exchanging and/or integration of combined heat and power". Applied Thermal Engineering, 19, 1999, pp. 707-731.

[2]. T. Berntsson, C. Bengtsson, and R. Nordman. "Utilization of excess heat in the pulp and paper industry - A case study of technical and economic opportunities". Applied Thermal Engineering, 22, 2002, pp. 1069-1081.
[3]. A. Carlsson, P.-A. Franck, and T. Berntsson. "Design better heat exchanger network retrofits". Chemical Engineering Progress 89, 1993, pp. 87-96.

[4]. M.M. El-Halwagi and V. Manousiouthakis. "Synthesis of mass exchange networks". AIChE Journal, 35, 1989, pp. 1233-1244.

[5]. S.G. Hall, S. Ahmad, and R. Smith. "Capital cost targets for heat exchanger networks comprising mixed materials of construction, pressure ratings and exchanger types". Computers \& Chemical Engineering, 14, 1990, pp. 319-335.

[6]. S. Lafourcade, J. Labidi, R. Koteles, C. Gélinas, P.R. Stuart. "Thermal pinch analysis with process streams mixing at a TMP-newsprint mill". Pulp and Paper Canada, 104 (12), 2003, pp. 74-77.

[7]. B. Linnhoff. "Use pinch analysis to knock dowm capital costs and emissions". Chemical Engineering Progress, August 1994, pp. 32-57.

[8]. B. Linnhoff, D.W. Townsend, D. Boland, G.F. Hewitt, B.E.A. Thomas, A.R. Guy, and R.H. Marsland. User Guide on Process Integration for the Efficient Use of Energy. The Institution of Chemical Engineers, Rugby, U.K., 1982.

[9]. R. Nordman and T. Berntsson. "New pinch technology based HEN analysis methodologies for cost-effective retrofitting". Canadian Journal of Chemical Engineering, 79, 2002, pp. 655-662.

[10]. M.A.S.S. Ravagnani, A.P. Da Silva, and A.L. Andrade. "Detailed equipment design in heat exchanger networks synthesis and optimisation". Applied Thermal Engineering 23, 2003, pp. 141-151.

[11]. L. Savulescu, B. Poulin, A. Hammache, and S. Bedard. "Water and energy savings at a kraft paperboard mill using process integration”. Annual Meeting - Technical Section, Canadian Pulp and Paper Association, Preprints, Pulp and Paper Technical Association of Canada, Montreal, Que., Canada, 2001. pp. 183-186.

[12]. L.E. Savulescu, M. Sorin, and R. Smith. "Direct and indirect heat transfer in water network systems". Applied Thermal Engineering 22, 2002, pp. 981-988. 